Original Article

\title{
The impact of walking speed on interlimb coordination in individuals with Parkinson's disease
}

\author{
Cheng-Chieh Lin, ScD ${ }^{1}{ }^{*}$, Robert C. Wagenaar, PhD ${ }^{2)}$ \\ 1) Department of Physical Therapy, Tzu Hui Institute of Technology: No. 367 Sanmin Rd., \\ Nanjhou Hsian, Pingung County 926, Taiwan \\ 2) Department of Physical Therapy and Athletic Training, Center for Neurorehabilitation, \\ College of Health and Rehabilitation Science, Sargent College, Boston University, USA
}

\begin{abstract}
Purpose] Interlimb coordination can be affected by the symptoms associated with Parkinson's disease and may result in an increased risk of falls. The purpose of the current study was to compare changes in interlimb coordination in individuals with Parkinson's disease to healthy older adults while systematically manipulating walking speed. [Subjects and Methods] Participants walked on a treadmill while systematically increasing and decreasing the walking speed between 0.22 and $1.30 \mathrm{~m} / \mathrm{s}$. Kinematic data were collected by means of a three dimensional motion capture system. Dependent variables included the phase relation between arm and leg movements as well as between pelvic and thoracic rotation. [Results] Compared to healthy controls, an increased variability in relative phase between left and right arm swing, and smaller amplitude with arm, leg as well as less variability for the phase relation between thoracic and pelvic rotations were shown in individuals with Parkinson's disease. [Conclusion] The increased variability of phase relation between left and right arm swing may be related to the reduced out-of-phase forcing of the arm movements at the shoulders as a result of axial rigidity in Parkinson's disease. It deserves further investigation whether the improvement of the coordination between arms could result in the normalization of parkinsonian gait.

Key words: Coordination, Variability, Parkinson's disease
\end{abstract}

(This article was submitted Jul. 19, 2016, and was accepted Dec. 19, 2016)

\section{INTRODUCTION}

Limitations in walking ability can be observed in individuals with advanced Parkinson's disease (PD), and can eventually lead to serious consequences such as falls, fear of falling, and loss of independence ${ }^{1,2)}$. Individuals with PD display a reduced range of phase relations between transverse pelvic and thoracic rotations accompanied by a smaller standard deviation of the relative phase compared to healthy subjects, indicating reduced flexibility and variability in trunk coordination ${ }^{3,4)}$. These coordination changes have been shown to be associated with the presence of axial rigidity demonstrating a relationship between neurological symptoms and coordination patterns during gait ${ }^{3-5}$ ).

Interlimb coordination is essential for stable, smooth and economical walking ${ }^{6-9)}$. Studies examining the impact of PD on coordination of walking have found that the coordination between limb movements may be disrupted ${ }^{10-13)}$. Although the underlying mechanism remains unclear, the impaired interlimb coordination during walking was found to correlate with clinical symptoms (i.e. rigidity and bradykinesia), lower subscores in posture and gait on the United Parkinson's Disease Rating Scale, and also the severity of the degeneration of the dopaminergic system ${ }^{12}{ }^{13}$. However, a key limitation of previous studies on parkinsonian gait is that subjects were instructed to walk at their comfortable walking speed which is known to

*Corresponding author. Cheng-Chieh Lin (E-mail: carllin12@gmail.com)

(C2018 The Society of Physical Therapy Science. Published by IPEC Inc.

(c) $(-)$ This is an open-access article distributed under the terms of the Creative Commons Attribution Non-Commercial No Derivatives Cy NC ND (by-nc-nd) License. (CC-BY-NC-ND 4.0: https://creativecommons.org/licenses/by-nc-nd/4.0/) 
be slower compared to healthy older adults. Walking speed has been shown to significantly alter movement kinematics and the coordination of trunk and limb movements - in the absence of any disease condition ${ }^{9,14,15)}$. It is possible that the slower comfortable walking speed may account for the changes of interlimb coordination observed in PD.

The purpose of the current study is to compare changes of interlimb coordination in individuals with PD and in healthy older adults while systematically manipulating walking speed to determine the impact of PD symptoms on interlimb coordination while controlling for the effects of walking velocity.

\section{SUBJECTS AND METHODS}

Twenty-four PD and 26 healthy control subjects (HC) participated in the present study. The mean age and the ratio of number of females and males are significantly lower in PD than HC (Table 1). Individuals diagnosed with typical, idiopathic PD were recruited from the Department of Neurology at Boston Medical Center and from local support groups in the Boston area. Individuals with PD were part of a randomized clinical study ${ }^{16)}$, and the inclusion criteria were: (1) stable medication usage; (2) early to moderate stage of the disease (Hoehn and Yahr stage II or III (Table 2)); (3) a rigidity score of at least 1 point for one of the extremity sub-items of the Unified Parkinson's Disease Rating Scale (UPDRS); (4) ability to walk independently; (5) age 35 to 75 years; (6) no severe cognitive impairments (Mini-Mental State Examination score $\geq 24$ ); and (7) no other severe neurologic, cardiopulmonary or orthopedic disorders. HC were screened via a medical history questionnaire and free from any significant history of cardiopulmonary, musculoskeletal, somatosensory, or neurological disorders. The study was approved by the Institutional Review Board at Boston University, and all participants provided written informed consent.

Participants were instructed to walk comfortably on a treadmill with computer-controlled speed, without holding the handrails. Standby supervision was provided to ensure safety. During the experiment, the speed of the belt was gradually increased from $0.22 \mathrm{~m} / \mathrm{s}$ to $1.30 \mathrm{~m} / \mathrm{s}$, in increments of $0.22 \mathrm{~m} / \mathrm{s}$, and then decreased in similar steps to $0.22 \mathrm{~m} / \mathrm{s}$. Each speed condition was maintained for about 1 minute, and movements of body segments were recorded for 30 seconds.

Three dimensional (3D) kinematic data were collected using an Optotrak 3020 system (Northern Digital Inc., Waterloo, ON, Canada). Infrared light emitting diodes (IREDs) were placed bilaterally on the following bony landmarks: foot (fifth metatarsal head), heel (calcaneus), ankle (lateral malleolus), knee (lateral femoral condyle), hip (greater trochanter), thigh (one third of the distance between knee and hip IRED), wrist (radial styloid process), elbow (lateral epicondyle), shoulder (acromion process), and head (zygomatic arch). Additionally, four IREDs were attached to the ends of two T-bars, which were mounted on harnesses and fixated around the hip and thorax to record pelvic and thoracic rotations in the transverse plane. The instantaneous positions of each IRED were sampled at a rate of $100 \mathrm{~Hz}$, and were stored on a PC for further off-line processing.

Leg swing angle in the sagittal plane was determined by the orientation angle between the projection of line of gravity and long axis of the leg defined by the hip and ankle marker. Arm swing in the sagittal plane was determined in a similar manner as leg swing mentioned above. The long axis of arm was defined by the shoulder and wrist marker. Transverse thoracic and pelvic rotation was obtained by calculating the orientation angle between the line of two markers fixed on the thoracic and pelvic T-bar and the axis of absolute Cartesian coordinate signifying mediolateral direction, respectively.

Point estimate of relative phase (PERP) between body segments was calculated by using the moment $\left(t_{\text {limbx }}\right.$ and $\left.t_{\text {limby }}\right)$ at which the positive maxima were reached for the angle of each body segment with the following equation ${ }^{17)}$ :

$$
\theta(i)=\frac{\operatorname{tlimby}(i)-\operatorname{tlimbx}(i)}{\operatorname{tlimbx}(i+1)-\operatorname{tlimbx}(i)}
$$

where $t_{\text {limby }}$ and $t_{\text {limbx }}$ represent (1) right arm and left arm (ORALA), (2) left leg and left arm (OLALL), (3) right leg and

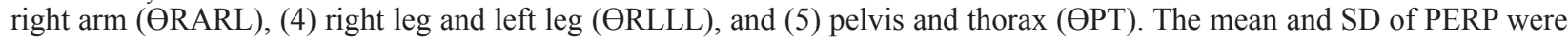
calculated by means of circular statistics ${ }^{18}$.

All statistical analyses were carried out with version 15.0 of SPSS statistical software package (SPSS, Inc. Chicago, IL, USA). The difference in age and gender between groups was examined by means of a Mann-Whitney $U$ test and a $\chi^{2}$ test, respectively. An ANOVA with repeated measures was performed for all dependent variables. If a significant interaction was found, post-hoc t-tests were performed. Due to significant differences in age and gender between PD and HC, both factors were included in the analyses of variance as covariates. The level of significance was set at 0.05 .

\section{RESULTS}

Table 2 presents the outcomes and statistics (F- and p-values) for all dependent variables.

A significant main effect of Age for mean $\Theta_{\text {LALL }}, F(1,45)=8.95, p<0.01$, indicates that older participants had larger mean $\Theta_{\text {LALL }}$ than younger participants. An interaction between Group and Speed was obtained for SD of $\Theta_{\text {RALA }}$. The variability of $\Theta_{\text {RALA }}$ decreased with the increasing speed, and was larger in PD than $\mathrm{HC}$ at all speeds with the exception of the slowest speed $(p<0.05)$ (Table 3). A significant main effect of Gender for SD of $\Theta_{R L L L}, F(1,45)=4.55, p=0.04$, indicates that $S D$ of 
Table 1. General characteristics of the individuals with Parkinson's disease (PD) and healthy controls subjects (HC)

\begin{tabular}{lcc}
\hline & PD & HC \\
\hline Number & 24 & 26 \\
Age (years, range)* & $62.2 \pm 9.7(37-75)$ & $72.3 \pm 5.6(63-84)$ \\
Gender (male/female)* & $20 / 4$ & $14 / 12$ \\
Hoehn and Yahr score & & \\
2 & 16 & NA \\
2.5 & 2 & NA \\
3 & 6 & NA \\
\hline$* \mathrm{p}<0.05$. & &
\end{tabular}

Table 3. Standard deviation (SD) for relative phase (RP) between left and right arm swing (degree) with increasing speed (meter per second) in individuals with Parkinson's disease (PD) and healthy control subjects (HC)

\begin{tabular}{ccc}
\hline Speed $(\mathrm{m} / \mathrm{s})$ & PD & HC \\
\hline 1 & $32.9 \pm 17.9$ & $41.9 \pm 22.9$ \\
2 & $29.0 \pm 17.4^{*}$ & $19.6 \pm 14.0$ \\
3 & $26.5 \pm 15.3^{*}$ & $17.2 \pm 14.7$ \\
4 & $21.9 \pm 16.0^{*}$ & $10.2 \pm 7.7$ \\
5 & $19.7 \pm 12.1^{*}$ & $8.6 \pm 6.7$ \\
6 & $13.9 \pm 10.6^{*}$ & $6.0 \pm 2.5$ \\
\hline
\end{tabular}

$* p<0.05$.
Table 2. Main and interaction effects of Speed (S), and Group $(\mathrm{G})$ for the means and standard deviation (SD) of arm and leg swing and trunk rotation

\begin{tabular}{|c|c|c|c|}
\hline & Speed (S) & Group (G) & $\mathrm{S}^{*} \mathrm{G}$ \\
\hline & F & F & $\mathrm{F}$ \\
\hline$\Theta_{\text {RALA}^{* \S}}$ & 26.27 & 6.60 & 0.35 \\
\hline SD $\Theta_{\text {RALA }^{*} \S}$ & 47.68 & 12.26 & 1.44 \\
\hline$\Theta_{\mathrm{RLLL}^{* \S}}$ & 13.34 & 11.34 & 0.91 \\
\hline $\mathrm{SD} \Theta_{\mathrm{RLLL} *+}$ & 53.41 & 0.34 & 3.75 \\
\hline$\Theta_{\text {LALL*\$§ }}$ & 29.56 & 4.58 & 2.83 \\
\hline $\mathrm{SD} \Theta_{\text {LALL* }}$ & 16.26 & 0.74 & 0.97 \\
\hline$\Theta_{\mathrm{RARL}^{*}}$ & 20.31 & 0.45 & 2.14 \\
\hline $\mathrm{SD} \Theta_{\mathrm{RARL}} *$ & 23.61 & 2.11 & 0.86 \\
\hline$\Theta_{\mathrm{PT} * \S}$ & 54.08 & 29.70 & 6.03 \\
\hline $\mathrm{SD} \Theta_{\mathrm{PT} * \S 9}$ & 3.38 & 5.42 & 3.0 \\
\hline
\end{tabular}

$\mathrm{F}$ and $\mathrm{p}$ indicate the $\mathrm{F}$ and $\mathrm{p}$ values of the analyses of variance. RALA: right arm and left arm; RLLL: right leg and left leg; LALL: left arm and left leg; RARL: right arm and right leg; PT: pelvis and thorax. * Significant main effect of Speed, §Significant main effect of Group, OSignificant interaction effect between Speed and Group.

$\Theta_{\text {RLLL }}$ was larger in males than females.

An interaction between Group and Speed was observed for mean $\Theta \mathrm{P}_{\mathrm{T}}$. The mean $\mathrm{\Theta P}_{\mathrm{T}}$ increased with speed for both groups with larger values in $\mathrm{HC}$ than $\mathrm{PD}$ at all speeds $(\mathrm{p}<0.03)$, and the difference between groups increased with speed.

A significant main effect of Age for SD of $\Theta_{\mathrm{PT}}, \mathrm{F}(1,43)=9.26, \mathrm{p}<0.01$, indicates that $\mathrm{SD}$ of $\Theta_{\mathrm{PT}}$ was larger in elderly participants than younger participants.

\section{DISCUSSION}

Walking speed is an important control parameter for coordination of walking and can be used as a basis for the evaluation of normal and pathological gait. The main purpose of the present study was to control the effects of walking speed to examine the impact of PD on the flexibility and stability of the coordination of arm and leg movements in persons with PD.

Our study extends the previous findings by showing that the variability of coordination between arms was significantly larger in PD compared to healthy adults while controlling for the walking speed. This suggests that PD symptoms, and not slow walking velocity, contributes to the impaired interlimb coordination between the arms. On the other hand, the lack of group difference for the coordination between left and right leg movements and between ipsilateral arm and leg movements may be due the pacing or cueing effect of the treadmill ${ }^{19}$.

The increased variability in relative phase between left and right arm movements in individuals with PD compared to the healthy subjects indicates that right and left arm in PD reached their peak rotation angles at variable moments in the stride cycle. This finding also suggests that not only the coordination of the individual arm swings but also the coordination between left and right arm swing is affected. The increased variability in the coordination of left and right arm movements during walking may be explained by the smaller transverse thoracic rotation, which reduces the out-of-phase forcing of the arm movements at the shoulder joints ${ }^{20)}$. It is hypothesized that the reduced out-of-phase forcing at the shoulder joints will result in a weaker out-of-phase coupling between the left and right arm movements and, therefore, an increased variability in relative phase between the arms. The importance of coordination of arm movements during walking has been demonstrated from the studies investigating the effect of restricting arm swing during walking in which decreased joint angle, stride length and walking speed and increased stride frequency and energy expenditure were reported while walking without arm swing ${ }^{21,22)}$. The increased variability of gait parameters such as stride and swing time has been associated with an increased risk of fall in individuals with $\mathrm{PD}^{11,23)}$. Hence, our findings of an increased variability of coordination between arms suggest that the normalization of coordination between arms should be incorporated into the rehabilitation plan to improve the parkinsonian gait. 
The present study has several limitations. As mentioned above, the cueing effect of treadmill may contribute to the reduced group differences in interlimb coordination ${ }^{24)}$. Moreover, all participants in the present study were able to walk at the highest walking speed, and therefore had a high functional status. The generalizability of the results in the present study to individuals with PD with more severe neurological symptoms and lower functional status as well as with different dominant symptoms may be limited ${ }^{25)}$.

The results of present study reveals altered coordination dynamics during walking in PD at a variety of walking velocities. The application of force driven pendulum models combined with EMG recordings may provide us with more accurate estimation of stiffness and interlimb coupling strength in parkinsonian gait ${ }^{26)}$. In addition, future study should include individuals with PD at different disease stages to obtain a better understanding of the progress of the disease and its effects on the gait dynamics. In summary, individuals with PD display an increased variability in relative phase between arm movements in comparison to older adults which coincides with decreased amplitude in arm and leg movements, and transverse thoracic, pelvic, and trunk rotations.

\section{ACKNOWLEDGEMENTS}

We are deeply grateful to all the individuals who participated in this study. We dedicate this paper to the memory of our colleague and friend, Robert C. Wagenaar.

\section{Conflict of interest}

None of the authors reports a conflict of interest.

\section{REFERENCES}

1) Martignoni E, Godi L, Citterio A, et al. Parkinson's Disease Comorbidity Study Group: Comorbid disorders and hospitalisation in Parkinson's disease: a prospective study. Neurol Sci, 2004, 25: 66-71. [Medline] [CrossRef]

2) Balash Y, Peretz C, Leibovich G, et al.: Falls in outpatients with Parkinson's disease: frequency, impact and identifying factors. J Neurol, 2005, 252: 1310-1315. [Medline] [CrossRef]

3) Van Emmerik RE, Wagenaar RC, Winogrodzka A, et al.: Identification of axial rigidity during locomotion in Parkinson disease. Arch Phys Med Rehabil, 1999, 80: 186-191. [Medline] [CrossRef]

4) Wagenaar RC, Van Emmerik RE: Dynamics of pathological gait. Hum Mov Sci, 1994, 13: 441-471. [CrossRef]

5) van Emmerik RE, Wagenaar RC: Dynamics of movement coordination and tremor in Parkinson's disease. Hum Mov Sci, 1996, 15: 203-235. [CrossRef]

6) Li Y, Wang W, Crompton RH, et al.: Free vertical moments and transverse forces in human walking and their role in relation to arm-swing. J Exp Biol, 2001, 204: 47-58. [Medline]

7) Krasovsky T, Baniña MC, Hacmon R, et al.: Stability of gait and interlimb coordination in older adults. J Neurophysiol, 2012, 107: 2560-2569. [Medline] [CrossRef]

8) Reisman DS, Block HJ, Bastian AJ: Interlimb coordination during locomotion: what can be adapted and stored? J Neurophysiol, 2005, 94: 2403-2415. [Medline] [CrossRef]

9) van Emmerik RE, Wagenaar RC: Effects of walking velocity on relative phase dynamics in the trunk in human walking. J Biomech, 1996, 29: 1175-1184. [Medline] [CrossRef]

10) Huang X, Mahoney JM, Lewis MM, et al.: Both coordination and symmetry of arm swing are reduced in Parkinson's disease. Gait Posture, 2012, 35: 373-377. [Medline] [CrossRef]

11) Plotnik M, Giladi N, Hausdorff JM: Bilateral coordination of walking and freezing of gait in Parkinson's disease. Eur J Neurosci, 2008, 27: 1999-2006. [Medline] [CrossRef]

12) Roemmich RT, Field AM, Elrod JM, et al.: Interlimb coordination is impaired during walking in persons with Parkinson's disease. Clin Biomech (Bristol, Avon), 2013, 28: 93-97. [Medline] [CrossRef]

13) Winogrodzka A, Wagenaar RC, Booij J, et al.: Rigidity and bradykinesia reduce interlimb coordination in Parkinsonian gait. Arch Phys Med Rehabil, 2005, 86: 183-189. [Medline] [CrossRef]

14) Donker SF, Beek PJ, Wagenaar RC, et al.: Coordination between arm and leg movements during locomotion. J Mot Behav, 2001, 33: 86-102. [Medline] [CrossRef]

15) Wagenaar RC, van Emmerik RE: Resonant frequencies of arms and legs identify different walking patterns. J Biomech, 2000, 33: 853-861. [Medline] [CrossRef]

16) Ellis T, de Goede CJ, Feldman RG, et al.: Efficacy of a physical therapy program in patients with Parkinson's disease: a randomized controlled trial. Arch Phys Med Rehabil, 2005, 86: 626-632. [Medline] [CrossRef]

17) Chou YH, Wagenaar RC, Saltzman E, et al.: Effects of optic flow speed and lateral flow asymmetry on locomotion in younger and older adults: a virtual reality study. J Gerontol B Psychol Sci Soc Sci, 2009, 64: 222-231. [Medline] [CrossRef]

18) Batschelet E: Circular statistics in biology. London: Academic Press.

19) Frenkel-Toledo S, Giladi N, Peretz C, et al.: Treadmill walking as an external pacemaker to improve gait rhythm and stability in Parkinson's disease. Mov 
Disord, 2005, 20: 1109-1114. [Medline] [CrossRef]

20) Kubo M, Wagenaar RC, Saltzman E, et al.: Biomechanical mechanism for transitions in phase and frequency of arm and leg swing during walking. Biol Cybern, 2004, 91: 91-98. [Medline] [CrossRef]

21) Eke-Okoro ST, Gregoric M, Larsson LE: Alterations in gait resulting from deliberate changes of arm-swing amplitude and phase. Clin Biomech (Bristol, Avon), 1997, 12: 516-521. [Medline] [CrossRef]

22) Sigg JA, Ives JA, Gaba JC, et al.: Effect of arm position on parameters of normal gait in older persons. Clin Kinesiol, 1997, 51: 33-36.

23) Baltadjieva R, Giladi N, Gruendlinger L, et al.: Marked alterations in the gait timing and rhythmicity of patients with de novo Parkinson's disease. Eur J Neurosci, 2006, 24: 1815-1820. [Medline] [CrossRef]

24) Pohl M, Rockstroh G, Rückriem S, et al.: Immediate effects of speed-dependent treadmill training on gait parameters in early Parkinson's disease. Arch Phys Med Rehabil, 2003, 84: 1760-1766. [Medline] [CrossRef]

25) Jankovic J, McDermott M, Carter J, et al. The Parkinson Study Group: Variable expression of Parkinson's disease: a base-line analysis of the DATATOP cohort. Neurology, 1990, 40: 1529-1534. [Medline] [CrossRef]

26) Holt KG, Wagenaar RC, LaFiandra ME, et al.: Increased musculoskeletal stiffness during load carriage at increasing walking speeds maintains constant vertical excursion of the body center of mass. J Biomech, 2003, 36: 465-471. [Medline] [CrossRef] 